\title{
Spirituality and Healthy Lifestyle Behaviors: Stress Counter-balancing Effects on the Well-being of Older Adults
}

\author{
GRACIE H. BOSWELL, EVA KAHANA, and \\ PEGGYE DILWORTH-ANDERSON
}

\begin{abstract}
The goal of this study was to examine stress-ameliorating effects of religiosity, spirituality, and healthy lifestyle behaviors on the stressful relationship of chronic illness and the subjective physical well-being of 221 older adults. We also investigated whether the intervening variables functioned as coping behaviors and orientations or as adaptations in late life. Guided by the stress paradigm, path analysis was used to assess these relationships in a stress suppressor model and a distress deterrent model. No suppressor effects were found; however a number of distress deterrent relationships were detected. Spirituality, physical activities, and healthy diet all contributed to higher subjective physical well-being, as counter-balancing effects, in the distress deterrent model. The findings have implications for future research on the role of spirituality, religiosity and lifestyle behaviors on the well-being of chronically ill older adults. Findings also support the need for studying different dimensions of religiosity and spirituality in an effort to understand coping versus adaptation in behaviors and orientations.
\end{abstract}

KEY WORDS: chronic illness related stressors; healthy lifestyle behaviors; religiosity; spirituality; physical well-being.

Gracie H. Boswell, Ph.D., M.Ed. (Case Western Reserve University) and (M. Ed.- Kent State University). She is a Carolina Program in Health and Aging Research Scientist at the Institute on Aging- University of North Carolina at Chapel Hill. Her research interests have been social gerontology and quality of life, emphasizing religiosity/spirituality.Eva Kahana, Ph.D. (University of Chicago) is Pierce T. and Elizabeth D. Robson Professor of Humanities and Director of the Elderly Care Research Center- Case Western Reserve University. Her research concentration has been the sociology of aging (coping \& stress and institutionalization).Peggye Dilworth-Anderson, Ph.D. (Northwestern University) is Director- Center for Aging and Diversity, Institute on Aging, Professor- School of Public Health, Department of Health Policy and Administration at University of North Carolina at Chapel Hill. Her research interests have been caregiving and minority health disparities. Correspondence to Gracie H. Boswell, Center for Aging \& Diversity, Institute on Aging, The University of North Carolina, 720 Martin Luther King Jr. Blvd., Chapel Hill, NC, USA; e-mail: gboswell@schsr.unc.edu. 


\section{Introduction}

There is a growing body of research investigating the well-being of older adults, while living with chronic illnesses. This is an important area of research given the number of people living with chronic illnesses, which presents a different set of challenges than experiencing episodes of acute illness (Royer, 1998). Chronic illness is pervasive in American society and may well be the source of stressors, impacting the subjective physical well-being of older adults. More than 125 million Americans were estimated to have chronic diseases in the year 2000 and by 2020 that figure is expected to rise to 157 million (The Robert Wood Johnson Foundation, 2002). Furthermore, chronic diseases account for about $70 \%$ of deaths in America and $75 \%$ of the costs of health care each year (Marks, 2003). These figures are expected to be compounded over the next 30 years, as the aging of the population over 65 is expected to double. For these reasons, studying the effects of stress associated with chronic illness on subjective physical well-being is timely.

Although there has been a great deal of research in the stress literature, there has not been enough empirical research on the relationships of religious or spiritual factors and healthy lifestyle behaviors to the well-being of older adults, while living with chronic illness (Sulmasy, 2002). Some social scientists believe that the investigation of the effects of religious and spiritual resources in addition to healthy lifestyle behaviors may be important (Harris, 1999; Oppenheimer, 1999). Based on a convergence of scientific interest in social science and medical research, the preponderant view of the literature has been that older adults tend to take more interest in spiritual pursuits than younger people (Koenig, 1997; Moberg, 2001; Sheehan, 2001). Schultz-Hipp (2001) posits that this is true even while controlling for cohort effects.

\section{Problem statement and hypotheses}

The purpose of this study was to understand more about how older adults maintain their subjective physical well-being, while living with chronic illnesses. We also wanted to know whether maintaining their physical well-being is due to "coping" or "adaptation," a rarely investigated concept. In order to study these questions we proposed three hypotheses: (1) Chronic illness related stressors negatively impact older adults' experiences of physical well-being. (2) Spirituality and private religiosity contribute to higher physical well-being among older adults.

(3) Healthy lifestyle behaviors contribute to higher physical well-being of older adults.

These hypotheses were simultaneously tested in stress suppressor and distress deterrent models. 


\section{Theoretical background}

Theories of stress and illness, along with supporting methodology, first evolved out of Selye's (1956) biomedical research. Since social scientists began to study stress sociologically, there have been three major ways to conceptualize and measure stressors that threaten well-being: life events, daily hassles, and chronic stressors. This study investigated chronic stressors, which are those that may be brought on by long-term illness and may be prevalent stressors in late life. According to Pearlin (1980), they may be even more deleterious to the individual's functional state than acute stressors because they are repetitive and last over a long period of time.

Generally, where chronic illness was experienced (Dekkers et al., 2001; Pakenham \& Rinaldis, 2001), stress research has investigated buffers of stress in attempting to address factors that affect poor health outcomes. Furthermore, most of the stress-buffering models have studied how stress affected an outcome of physical disability instead of outcomes of well-being. Resources that may buffer the impairment process included medical care, therapeutic regimens, social support, physical and social environments, lifestyle behaviors, psychosocial and religious coping (Gall, 2000; Pakenham \& Rinaldis, 2001; Stowell, Kiecolt-Glaser, \& Glaser, 2001).

Guided by stress theory, both stress suppressor and distress deterrent models were tested in this study. As shown in Figure 1, the distress deterrent model is embedded in the stress suppressor model. Because of the complimentary relationship between these models in understanding stress effects and ameliorating effects of stressors on outcomes, this study tested both models simultaneously. The theoretical suppressor model (Wheaton, 1985) is an additive effects buffering model and is stress responsive (i.e., More stressors are related to a higher level of intervening resources which may lead to a higher level of well-being). The distress deterrent model is a stress counterbalancing model (Aneshensel, 1992; Krause \& Van Tran, 1989; Wheaton, 1985) and allows for understanding non-stress responsive relationships (i.e., If stressors are not related to intervening resources, a higher level of well-being can still be experienced due to direct effects). In this study the suppressor model was used to understand the role of "coping" and the distress deterrent model was used to conceptualize the role of "adaptation" in ameliorating the effects of illness related stressors on physical well-being among older adults.

Coping and adaptation in this study focused on religious and spiritual orientation and healthy life-style behaviors of chronically ill older adults to help lessen the effects of illness related stressors on their physical well-being. Coping is defined here as a subset of adaptation and involves effort commensurate with the level of stress (Compas, Connor, Osowiechi, and Welch, 1997). It is not an automatic action that takes place regardless of the presence of stressors. In addition, coping may also be a process that changes over time. On the other hand, adaptations are defined in this study as rituals and practices that are automatic, ingrained in the cultural fabric of the society in 


\section{FIGURE 1}

Theoretical Model to Test Stress Suppressor and Embedded Distress Deterrent Relationships. Notes a. For Parsimony of Presentation, the Sociodemographics and Some Paths are not Shown. b. Paths 2 and 5 Suppress the Relationship of Path 7 in the Directions Shown. c. Paths 4 and 5, \& 6 Respectively, Counter-Balance (Distress Deterrent) the Relationship of Path 7

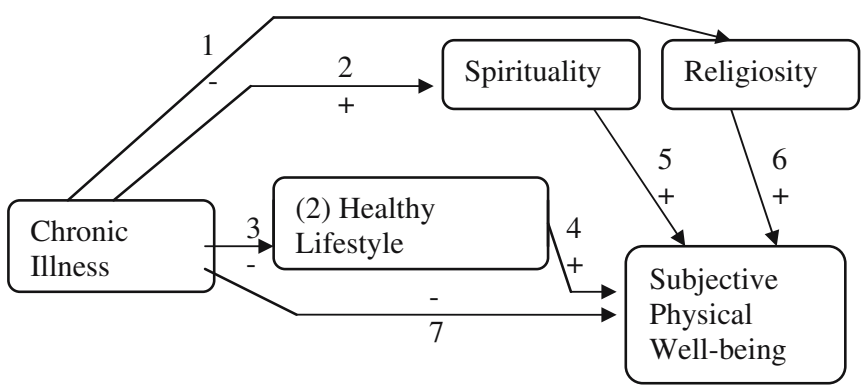

which individuals have developed over time and may be performed automatically or without effort as a part of everyday behavior (Lazarus \& Folkman, 1991). Adaptations are not stress responsive and may take place regardless of the presence of stressors.

The suppressor model allowed for analyzing the ways in which the orientations serve as additive effects buffers. Complementary to this, the distress deterrent model showed how certain orientations and behaviors directly ameliorated the negative effects of stress on physical well-being. Using these two models, we were able to examine how each allowed for explaining whether religious and spiritual orientations and healthy behaviors, either through coping or adaptation, resulted in reducing illness related stressors.

\section{Methods}

Sample and data collection

The sample for this study includes 221 older adults, age 65 and older, who were part of an NIA funded study R01 AG 01658. That larger study was randomly selected from Medicare lists and known as the Cleveland Health Maintenance Study (CHMS). Participants lived in northeast Ohio, and at baseline in TIME1 1999, 365 older adults were interviewed face-to-face during the first wave of the study. During the two-year follow-up, 343 respondents were interviewed, reflecting a response rate at TIME 2 of 94\%. However, only 221 of the participants were used in this study, representing those who responded to a TIME2 follow-up interview. 


\section{Attrition}

Table 1 illustrates the characteristics of those respondents who were used in the follow-up interview and those who were lost to attrition due to death, refusal, and loss to follow-up. There were significant differences between the sample characteristics of those respondents who were used in the follow-up interview and those who were lost to attrition in the demographic categories of gender and race. More women and African Americans remained in the sample than were lost to attrition, but these two variables were not variables that were examined in this study. Additionally, there were no significant group differences between the retained sample and the attrition group in terms of age, education, public religiosity, private religiosity, illnesses, or healthy diet.

\section{The sample characteristics}

Characteristics of the sample are illustrated in Table 2. Additional descriptive statistics (not shown) revealed that $86 \%$ of the sample data were in the 75 or older age category, which consisted of $76 \%$ females and $24 \%$ males. Approximately $82 \%$ of the sample was White and $18 \%$ was Black. People in the lower socioeconomic statuses were notably represented in the sample with about one third having less than a high school education and $40 \%$ having a household income below $\$ 15,000$ per year. In addition, a majority of the sample (93\%) reported having been diagnosed with at least 1 chronic disease on the OARS Chronic Illness Inventory (George \& Fillenbaum, 1985).

TABLE 1

Characteristics of Follow-up Study Respondents and Those Who Were Lost to Attrition

\begin{tabular}{lllcrc}
\hline Characteristic & Sample (221) & Attrition (122) & $t$ & $\chi^{2}$ & $p$ \\
\hline Age (years) & $80.2(5.3)$ & $79.9(6.1)$ & .906 & $\mathrm{~ns}$ \\
Education (years) & $12.6(3.3)$ & $13.1(3.7)$ & -1.167 & & $\mathrm{~ns}$ \\
Gender (\% female) & 75.6 & 65.6 & & .048 & $<.05$ \\
Race (\% white) & 82.3 & 70.8 & & .028 & $<.05$ \\
Public Religiosity & $6.6(2.9)$ & $6.4(2.6)$ & .802 & $\mathrm{~ns}$ \\
Private Religiosity & $14.94(5.7)$ & $14.44(5.5)$ & .961 & $\mathrm{~ns}$ \\
Illness (total \#) & $2.1(1.2)$ & $2.1(1.5)$ & -.122 & $\mathrm{~ns}$ \\
Healthy diet & $3.9(1.1)$ & $4.0(1.2)$ & -.743 & $\mathrm{~ns}$ \\
\hline
\end{tabular}

Note. $N=221, d f=2$ for each $F$ and $\chi^{2}$ (gender; $d f=1$ ); HS education, gender, race are all \%'s; other values are means and (standard deviations). Attrition was due to death, refusal, and loss to follow-up. 
TABLE 2

Descriptive Statistics of the Sample Variables

\begin{tabular}{lrrrrr}
\hline Variables & Mean & SD & Range & Skewness & Kurtosis \\
\hline Age (years) & 80.21 & 5.38 & 32 & -.28 & .52 \\
Gender (F = 1) & .76 & - & - & - & - \\
Race (B = 1) & .18 & - & - & - & - \\
Education (years) $_{\text {Income }^{\mathrm{a}}}$ & 12.56 & 3.28 & 22 & .14 & 2.03 \\
\# Chronic Illnesses & 24.96 & 19.56 & 72.5 & 1.52 & 1.52 \\
Spirituality $_{\text {Public Religiosity }}$ & 2.10 & 1.25 & 7 & .49 & .30 \\
Private Religiosity & 17.03 & 4.04 & 17 & -.50 & -.39 \\
Physical Activity & 6.52 & 2.86 & 12 & .34 & -.78 \\
Healthy Diet & 14.94 & 5.75 & 16 & -.87 & -.68 \\
Subjective Physical Well-being & 11.56 & 1.99 & 10 & -.31 & .24 \\
\hline
\end{tabular}

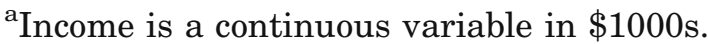

\section{Measures}

Demographic and other control variables. Age and education were measured as continuous variables. Race was coded as White $=0$ and Black $=1$. Gender was coded as male $=0$ and female $=1$. Income was recoded with factors from 2.5 to 75 , based on mean values of $\$ 5000$ increments, and divided by 1000 .

Subjective physical well-being. It was a 3 item composite created from CHMS survey items and reverse coded on 5-point Likert scales, with a reliability of Cronbach's $\alpha=.78$ for the sample: (1) In general, do you consider yourself to be a very healthy, healthy, fairly healthy, sick, or very sick person? from 1 (very sick) to 5 (very healthy); (2) Considering your health over the past year, would you say your health is excellent, good, fair, poor, or very poor? from 1 (very poor) to 5 (excellent); and (3) Compared to other people your age, would you say that your health is much better, better, about the same, worse, or much worse over the past year? from 1 (much worse) to 5 (much better). Composite scores ranged from 3 (low) to 15 (high), mean $=11.56, S D=1.99$.

Chronic illness. The OARS Chronic Illness Index (George \& Fillenbaum, 1985) indicated if participants had any of the following 10 chronic illnesses over the past year: arthritis, asthma, emphysema, hypertension, heart trouble, diabetes, urinary tract problems, cancer, stroke, and orthopedic problems. Similar illness indices were supported in prior research as part of their 
research methodologies (Porell \& Miltiades, 2001; Shaw \& Krause, 2001). Scores ranged from 0 to 10 diseases, mean $=2.1, S D=1.25$.

Healthy lifestyle behaviors. The two measures used were physical activity and healthy diet. The term physical activity was used instead of exercise because many older adults engage in activities that may not be classified as exercise but may still be a part of an active lifestyle. Physical activity was measured as a continuous variable based on total hours per week that participants engaged in: walking as exercise, swimming, golfing, running, aerobics, stretching, weight lifting, dancing, bicycling or exercise machines, exercise for therapy or other exercises, household activities, gardening/lawn care, home repairs, and all other walking and activities. Scores ranged from 0 to 20 hours of activity, mean $=19.06, S D=16.0$. Participants' adherence to healthy diets were assessed using responses from the CHMS questionnaire and measured on a 5-point Likert scale from 1 (not at all) to 5 (very much), mean $=3.97, S D=1.11$. Skewness (1.53) or kurtosis (3.01) on physical activity did not indicate violation of cutoffs (Kline, 1998), especially when you consider that the average age of the respondents was 80 .

Spirituality. Spirituality was defined as experiencing transcendence through inner peace, harmony, or connectedness to others. Any one or all of these qualities could be present.

Four items, with an internal reliability of Cronbach's $\alpha .=.79$ for this sample, were used from The Daily Spiritual Experiences Scale (Fetzer, 1999). These four items were reverse coded and used to measure spirituality on 6 -point Likert scales from 1 (never or almost never) to 6 (many times a day): (1) selfless caring for others, (2) connection to all of life, (3) deep inner peace or harmony, and (4) spiritually touched by the beauty of creation. A composite scale created from three Likert scales ranged from 6 (low) to 24 (high), mean $=17.03, S D=4.04$.

Religiosity. Religiosity was defined as the adherence to religious dogma or creed, the expression of moral beliefs, and/or the participation in organized or individual worship or sacred practices. Any one or all of these qualities may be present and the construct was measured in two dimensions as private and public religiosity. Private religiosity, with a reliability of Cronbach's $\alpha=.95$ for this sample, was a composite of 4 items. Three items from the Cope Inventory (Carver, Scheier, \& Weintraub, 1989) were each measured on a 5 -point Likert scale from 1 (never) to 5 (very often): (1) seek God's help, (2) trust in God, (3) find comfort in religion. Also, one item from the CHMS 2001 questionnaire measured on a 5-point Likert scale, from 1 (never) to 5 (several times a week): (4) frequency of prayer. Composite scores of Likert scales ranged from 4 to 20 , mean $=14.94, S D=5.75$. 
Public religiosity, with a reliability of Cronbach's $\alpha=.81$ for this sample, was a composite of 3 religious participation items from the CHMS 2001 questionnaire. (1) frequency of attendance at religious services during the past year measured on a 5-point Likert scale, from 1 (never) to 5 (several times a week). (2) take part in other activities besides regular services, at your place of worship measured on a 5-point Likert scale from 1 (never) to 5 ( $4+$ times a week): (3) frequency of participation in other church or synagogue activities was reverse coded and measured on a 5-point Likert scale from 1 (rarely or never) to 5 (several hours a day). Composite scores ranged from 3 to 15, mean $=6.52, S D=2.86$.

\section{Preliminary data analysis}

A number of tests were performed on the data. Limits for influential cases were computed and cutoffs for outliers were tested and confirmed acceptable. Diagnostics in the tests for assumptions of multiple regressions reflected nonlinear patterns for some variables. This is not unusual among mostly chronically ill older adult populations (i.e., physical activity).

As a preliminary screening for possible multicollinearity in the model, a Pearson Correlation matrix was examined. Correlation results prompted running tolerance tests. Sample variable tolerances ranged from .511 to .921 ( perfect tolerance $=1.00$ ), illustrating moderate multicollinearity, given there are no perfect tolerance levels.

Results of face validity for the religiosity and spirituality constructs followed by Exploratory Factor Analysis (EFA) in SPSS were the basis for using a briefer version of The Daily Spiritual Experiences Scale (DSES) (Fetzer, 1999) consisting of only four items. These findings, illustrated in Table 3, support the work of Underwood and Teresi (2002), whose recent work testing content validity created a different brief DSES.

Moving forward in the analysis, path analysis was then used (Gogineni, Alsup, \& Gillespie, 1995) to test the three hypotheses in the suppressor model. As a result of path analysis, the distress deterrent model emerged in the resulting significant paths, but the suppressor model did not result in significant paths.

\section{Results}

Predicting illness stressors, lifestyle, and religiosity or spirituality on physical well-being

The fit of the statistical suppressor model with the imbedded distress deterrent model was illustrated as a good fit to the data by the statistic $F(11,209)=7.397, p<.001$ and is appropriate for testing the hypotheses of this study. Therefore, the path coefficients, representing the suppressor and 
TABLE 3

Exploratory Factor Analysis of Religiosity and Spirituality

\begin{tabular}{lccc}
\hline Factored Items & $\begin{array}{c}\text { Private } \\
\text { Religiosity }\end{array}$ & $\begin{array}{c}\text { Public } \\
\text { Religiosity }\end{array}$ & $\begin{array}{c}\text { Spiritual } \\
\text { Experiences }\end{array}$ \\
\hline I feel a selfless caring for others. & .241 & .121 & .578 \\
I experience a connection to all of life. & .111 & - & .806 \\
I feel a deep inner peace or harmony. & .209 & .159 & .629 \\
I am spiritually touched by the & .223 & .194 & .624 \\
$\quad$ beauty of creation. & .852 & .264 & .282 \\
I seek God's help. & .895 & .237 & .255 \\
I put my trust in God. & .856 & .259 & .278 \\
I find comfort in my religion. & .745 & .214 & .221 \\
How frequently do you pray? & .363 & .787 & - \\
Attend religious services? & .145 & .667 & .214 \\
Participation other than & & & \\
$\quad$ worship services? & .197 & .773 & .116 \\
Frequency of participation in church & & & \\
or synagogue activities? & & & \\
\hline
\end{tabular}

Note: Principal axis extraction was used. The rotation method which converged in 6 iterations was Varimax with Kaiser normalization.

distress deterrent effects on the physical well-being of the older adults in the sample are illustrated in Table 4. After statistically testing the hypotheses, we determined whether religiosity, spirituality, or lifestyle behaviors were suppressors of chronic illness related stressors on physical well-being or whether they were instead distress deterrent factors which countered the effects of chronic illness related stressors on physical wellbeing.

Hypothesis 1: Chronic illness related stressors negatively impacted older adults' experiences of physical well-being.

As predicted, chronic illness related stressors had a negative impact ( $\beta=-.326, p<.001)$ on physical well-being among older adults in the study. These results confirmed prior research showing the negative effects of chronic illnesses (Porell \& Miltiades, 2001; Shaw \& Krause, 2001). Therefore, hypothesis 1 could not be rejected. 


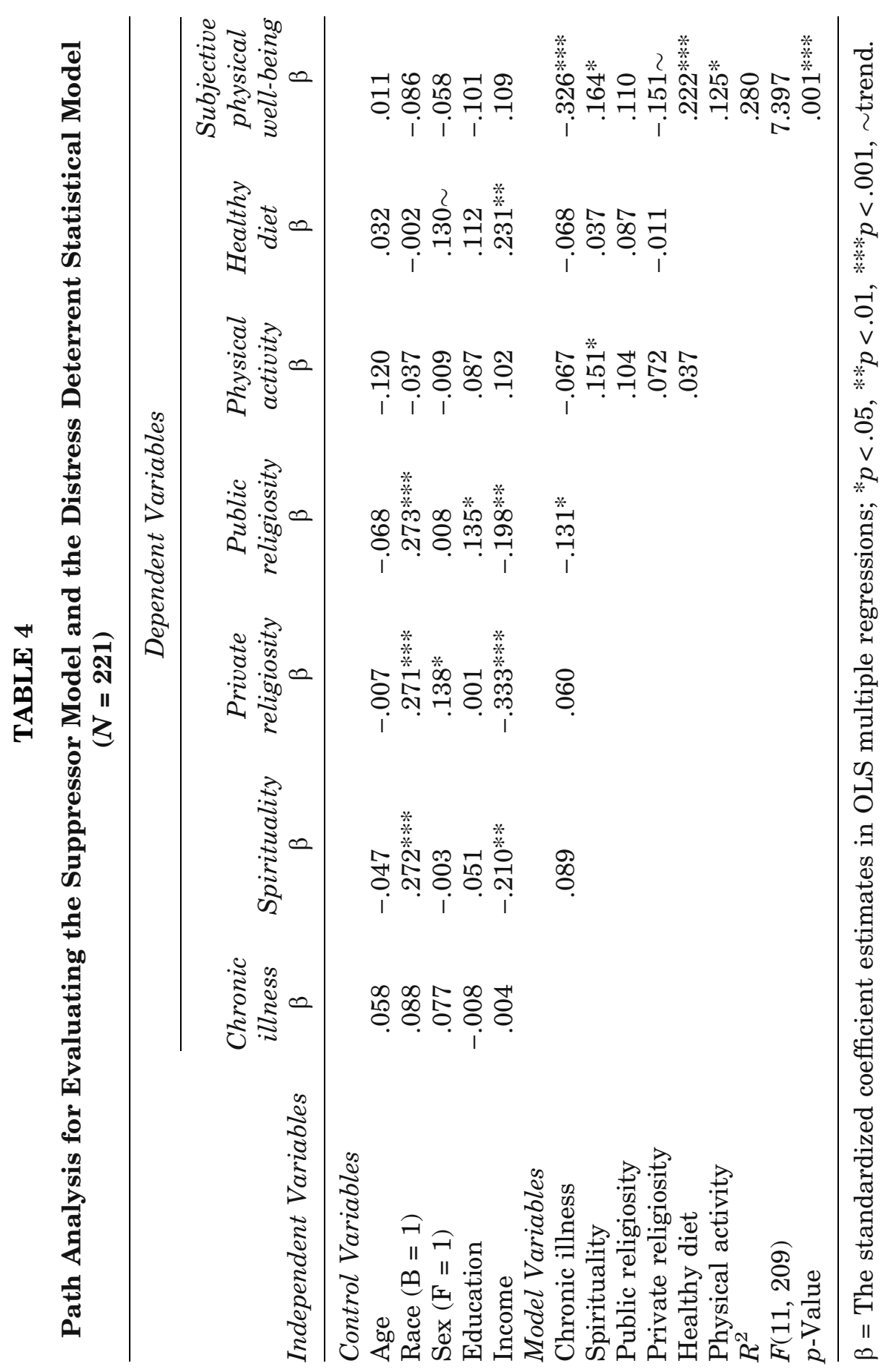


Hypothesis 2: Spirituality and private religiosity contribute to higher physical well-being among older adults.

Hypothesis 3: Healthy lifestyle behaviors contribute to higher physical wellbeing of older adults.

Both of the healthy lifestyle behaviors, physical activities $(\beta=.125, p<.05)$ and healthy $\operatorname{diet}(\beta=.222, p<.001)$, as well as spirituality $(\beta=.164, p<.05)$ contributed to higher subjective physical well-being of the older adults in the sample. Figure 2 illustrates that only these direct effects, showing distress deterrent relationships (Krause \& Van Tran, 1989; Wheaton, 1985), were significant effects of the intervening variables (lifestyle behaviors and spirituality). Based on theory, these relationships are adaptations, they are not responsive to stress and may be adaptations; hence they only had direct effects on physical well-being.

On the other hand, public religiosity was stress responsive $(\beta=-.131$, $p<.05)$. Therefore, it was not a distress deterrent resource. However, the negative effect and insignificant relationship to subjective physical well-being indicates that it was not a stress suppressor either. In fact, not only was public religiosity not found to be a suppressor, but none of the intervening variables tested (public or private religiosity, spirituality, diet or physical activity) were found to exert suppressor effects in the model (See Figure 2). Contrast these findings with Figure 1 which illustrates the necessary positive paths ( 2 and 5 ) leading to and from the intervening variables in order to be considered as suppressor effects.

Revealing findings were that neither public nor private religiosity served any type of stress ameliorating functions; however spirituality (spiritual experiences) did act as a distress deterrent, counter-balancing the negative effects of stressors associated with chronic illness on physical well-being. Nevertheless, because of the stress counter-balancing effects of spirituality and healthy lifestyle behaviors (diet and physical activity), Hypotheses 2 and 3 could not be rejected.

\section{Discussion}

Three hypotheses were formed for this research. The first hypothesis stated that chronic illness related stressors negatively impact older adults' experiences of physical well-being. Illness related stress effects on well-being may be partly due to a burden of stigma associated with ill health that older adults may carry, according to Baum, Jennings, Manuck, and Rabin (2000), which poses specific threats due to lasting changes in the physical self. This issue associated with self-image could compound the stress of having a chronic 


\section{FIGURE 2}

Significant Paths Resulting from Testing the Theoretical Suppressor Model and Distress Deterrent Models. Bold paths and concepts represent only distress deterrent relationships. (a) Path coefficient of healthy diet is $(\beta=.222, p \leq .001)$. (b) Path coefficient of physical activity is $(\beta=.125, p \leq .05)$. (c) Path coefficient of spirituality (spiritual experiences) is $(\beta=.164, p \leq .05)$

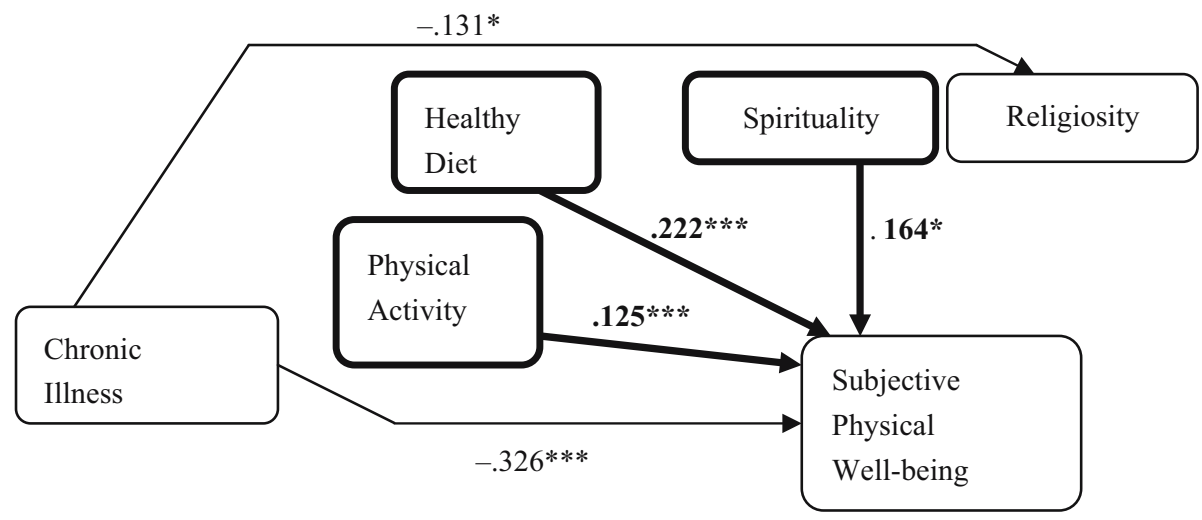

illness (Charmaz, 2000). Understanding stress effects of illness helps to know how some people make the most of life, experiencing well-being in the face of illness. It was useful in conceptualizing both stress and "coping" and stress and "adaptation" in both the suppressor model and the distress deterrent model, which was embedded in the stress suppressor model of Figure 1 and illustrated in Figure 2 (Krause \& Van Tran, 1989).

The second hypothesis stated that spirituality and private religiosity contribute to higher physical well-being among older adults. As illustrated by the negative path 7 in Figure 1, chronically ill older adults with a mean age of 80 years were not expected to exhibit strong public religiosity, and results supported this. On the other hand, these data neither supported coping by private religiosity behaviors nor spirituality (e.g., daily spiritual experiences) as responses to stressors. Because of the absence of these positive significant relationships as illustrated in the theoretical model of Figure 2, a suppressor model was not supported as conceptualized in Figure 1. Instead of these suppressor relationships, distress deterrent relationships emerged in the data (See Figure 2); and although these results were conceptually different, the stress-ameliorating outcome was the same, thereby revealing that more spiritual experiences lead to higher subjective physical well-being. The conceptual difference was that unlike suppressor relationships, spirituality was not stress responsive (i.e., no significant positive relationship between chronic 
stressors and spirituality). Because of this, hypothesis two could not be rejected due to the stress counter-balancing effects illustrated in the distress deterrent relationships of Figure 2 for spirituality.

The third hypothesis stated that healthy lifestyle behaviors contribute to higher physical well-being of older adults. It was expected that healthy lifestyle behaviors would be lower, with more chronic illness related stressors; therefore, suppressor effects were not expected. Findings were that healthy lifestyle behaviors, diet and physical activity, were not affected by chronic illness related stressors but still contributed to higher subjective physical wellbeing. Therefore, hypothesis three could not be rejected because of the positive impact of the lifestyle behaviors on subjective physical well-being. As indicated by their spirituality, the healthy lifestyle behaviors of the older adults in this sample were not dependent upon chronic illnesses. Therefore, the positive impact of these behaviors on their subjective physical well-being may be seen as a means of adaptation (i.e., not stress responsiveness). In other words, the behaviors could have happened with or without illness stressors, and perhaps illness was not considered a stressor, but a by-product of old age. These positive effects counter-balanced the negative effects of chronic illness stressors. According to the theoretical framework used in this study, these results may illustrate adaptation. Adaptation is viewed as automatic and directly impacts the outcome (Lazarus \& Folkman, 1991; Royer, 1998). This perspective is also applicable to the distress deterrent effects that were found for spirituality and healthy lifestyle behaviors on subjective physical wellbeing. On the other hand, coping intervenes between stressors and the outcome and has been described as a direct and effortful response to stress (Compas et al., 1997). These results appear to be consistent, at least in part, with Krause and Van Tran's (1989) findings that religiosity was not stress responsive, but was counter-balancing (distress deterrent), in an older adult population.

The suppressor model is one way of illustrating the tenets of coping, while on the other hand, the distress deterrent model may better illustrate the characteristics of adaptation. This study revealed that the older adults had spiritual experiences and maintained their healthy lifestyle behaviors whether or not they were chronically ill. Therefore, adaptation as opposed to coping was more indicative of their spiritual orientation and lifestyle behaviors.

We believe that the results of this study contribute to the literature by shedding more light on a less explored concept about ways of modeling stress and coping versus adaptation. Studying stress in this broader context, which is often overlooked, distinguishes between the different concepts and better addresses a means of interpreting the findings. The findings of this study are important in revealing that not only stress responsive coping mechanisms contribute to well-being, but non-stress responsive effects can contribute to physical well-being through adaptation to life circumstances. In this study, it 
appeared that adaptation was taking place whereby the older adults practiced healthier lifestyle behaviors through diet and exercise even regardless of their chronic illnesses. Additionally, this study builds upon stress research with a positive outcome as the focus (well-being). Focusing on more positive outcomes in the face of chronic illness, Kahana and Kahana's (1996, 2003) successful aging model emphasized the effects of lifestyles as proactive adaptations in ameliorating the effects of disability on subjective physical well-being. It also advances the seminal work of a prominent stress researcher, Antonovsky (1982), who wanted to know why some people experience greater well-being in the face of chronic illness than others.

We submit that the preponderant view of the literature is that older adults tend to take more interests in religious and spiritual pursuits than younger people (Moberg, 2001; Schultz-Hipp, 2001). However, this view did not explain why neither public nor private religiosity (trend or borderline significance) had significant effects on subjective physical well-being when tested in either the suppressor or the distress deterrent model. In order to address this question for public religiosity we considered the mean age (80 years) of respondents in the sample. With better than $86 \%$ of the sample over the age of 75 and an even higher percentage suffering from chronic illnesses, public religious participation, may not be a means of investigating religious involvement for the older adults in this study. Also, these data do indicate in descriptive statistics that most people relied on private religiosity, as evident by the mean level of public religiosity which was much lower compared to the mean level of private religiosity. This may be due to disability and lack of mobility associated with chronic illness. It may also partly explain the absence of significant effects of private religiosity on the outcome. Yet, since private religiosity is more intrinsic than public religiosity, not requiring public involvement, the results in these data do not readily explain the absence of either suppressor effects or distress deterrent effects on subjective physical well-being. Two considerations for these results are that the older adults in this study used negative adaptation in their private religiosity. It also appears that skew could have contributed to the lack of normal variability in the sample variable, and age of the sample could have affected the clustering on the scale and its low variability.

\section{Study limitations}

These findings must take into account the limitations of cross-sectional data, which may prevent accurate causal ordering at times. In addition, the religiosity measures may not generalize to elders who do not share Judeo-Christian beliefs. Despite these limitations, this research is an important start in investigating the impact of spirituality, religiosity, and lifestyle on subjective physical well-being among older adults, not only from the perspective of stress and coping but also in terms of stress and adaptation. 
Furthermore, this study validates a short form of the Daily Spiritual Experiences Scale. Underwood and Teresi (2002) found non-generalizability was true for many items of the Daily Spiritual Experiences Scale (Fetzer, 1999). However, the factor analysis performed in this study helped to explain more about the construct validity of this measure.

Future studies need to include more emphasis on adaptation as well as coping. This will offer more avenues toward understanding the findings of stress research when including spirituality and religiosity in an aging population. Different dimensions of religiosity and spirituality may be more effectively explicated when compared in different theoretical frameworks (i.e., suppressor and distress deterrent models).

\section{Acknowledgment}

This study was funded by the National Institute on Aging R03AG17682 and The Hall Award, Case Western Reserve University School of Medicine, Dept. of Medical Education.

\section{References}

Aneshensel, C. S. (1992). Social stress: Theory and research. Annual Review of Sociology, 18, $15-28$.

Antonovsky, A. (1982). Health, stress and coping. San Francisco: Jossey-Bass.

Baum, A., Jennings, R., Manuck, S. B., and Rabin, B. S. (2000). Behavior, health and aging. Mahwah, NJ: Lawrence Erlbaum Associates.

Carver, C. S., Scheier, M. F., and Weintraub, J. K. (1989). Asessing coping strategies: A theoretically based approach. Journal of Personality and Social Psychology, 66(1):184-195.

Charmaz, K. (2000). Experiencing chronic illness. In G. L. Albrecht, R. Fitzpatrick and S. C. Scrimshaw (Eds.Handbook of social studies in health and medicine (pp. 277-292). London: Sage Publications.

Compas, B. E., Connor, J., Osowiechi, D., and Welch, A. (1997). Effortful and involuntary responses to stress. In B.H. Gottlieb (Ed.Coping with chronic stress (pp. 105-129). New York: Plenum Press.

Dekkers, J. C., Geenen, R., Evers, A., Kraaimaat, F., Bijlsma, J., and Godaert, G. (2001). Biopsychosocial mediators and moderators of stress-health relationships in patients with recently diagnosed rheumatoid arthritis. Arthritis Care \& Research, 45, 307-316.

Fetzer Institute (1999). Multidimensional measurement of religiousness/spirituality for use in health research. Kalamazoo, Michigan: John E. Fetzer Institute Publication.

Gall, T. L. (2000). Integrating religious resources within a general model of stress and coping: Long-term adjustment to breast cancer. Journal of Religion and Health, 39(2):167-181.

George, L. and Fillenbaum, G. (1985). OARS methodology: A decade of experience in geriatric assessment. Journal of the American Geriatrics Society, 33a, 607-615.

Gogineni, A., Alsup, R., \& Gillespie, D. (1995). Mediation and moderation in social work research., National Association of Social Workers, Inc., Code: 1070-5309/95, 57-63.

Harris, J. W. (1999). To live is to change. In A. Jewell (Ed.Spirituality and aging (pp. 20-29). London: Jessica Kingsley Publishers.

Kahana, E. and Kahana, B. (1996). Conceptual and empirical advances in understanding aging well through proactive adaptation. In V. Bengston (Ed.Adulthood and aging: Research on continuities and discontinuities (pp. 18-41). New York: Springer Publishing Co. 
Kahana, E. and Kahana, B. (2003). Contextualizing successful aging: New directions in age-old search. In R. Settersten (Ed.Invitation to the life course: A new look at old age (pp. 225-255). Amityville, New York: Baywood Publishing Company.

Kline, R. B. (1998). Principles and practice of structural equation modeling. New York: The Guilford Press.

Koenig H. G. (1997). Is religion good for your health: The effects of religion on physical and mental health (pp. 49-75 \& 77-99). New York: The Haworth Pastoral Press.

Krause, N. and Tran, T.Van (1989). Stress and religious involvement among older blacks. Journal of Gerontology: Social Sciences, 44, S4-S14.

Lazarus, R. S. and Folkman, S. (1991). The concept of coping. In A. Monat and R. Lazarus (Eds.Stress and coping an anthology (pp. 189-206). New York: Columbia University Press.

Marks, J. S. (2003). The burden of chronic disease and the future of public health. United States Department of Health and Human Services Centers for Disease Control and Prevention. National Center for Chronic Disease Prevention and Health Promotion.

Moberg, D. O. (2001). The reality and centrality of spirituality. In D. O. Moberg (Ed.Aging and spirituality (pp. 3-20). New York: The Haworth Pastoral Press.

Oppenheimer, H. (1999). Inner resources for growing older. In A. Jewell (Ed.Spirituality and aging (pp. 39-47). London: Jessica Kingsley Publishers.

Pakenham, K. and Rinaldis, M. (2001). The role of illness, resources, appraisal, and coping strategies in adjustment to HIV/Aids: The direct and buffering effects. Journal of Behavioral Medicine, 24(3):259-279.

Pearlin, L. I. (1980). Life strains and psychological distress among adults. In L. Goldberger and S. Breznitz (Eds.Handbook of stress, theoretical and clinical aspects (pp. 367-379). New York: The Free Press.

Porell, F. and Miltiades, H. (2001). Access to care and functional status change among aged Medicare beneficiaries. Journal of Gerontology: Social Sciences, 56B, S69-S83.

Royer, A. (1998). Life with chronic illness: Social and psychological dimensions. Westport, CT: Praeger Publishers.

Schultz-Hipp, P. L. (2001). Do spirituality and religiosity increase with age?. In D.O. Moberg (Ed.Aging and spirituality (pp. 85-97). New York: The Haworth Pastoral Press.

Selye, H. (1956). The stress of life. New York: McGraw-Hill.

Shaw, B. and Krause, N. (2001). Exploring race variations in aging and personal control. Journal of Gerontology: Social Sciences, 56B, S119-S124.

Sheehan, M. (2001). Spirituality in later life.l. In S. E. Levkoff, Y. K. Chee and S. Noguchi (Eds.Aging in good health New York: Springer Publishing Co.

Stowell, J. R., Kiecolt-Glaser, J. K., and Glaser, R. (2001). Perceived stress and cellular immunity: When coping counts. Journal of Behavioral Medicine, 24(4):323-339.

Sulmasy, D. P. (2002). A biopsychosocial-spiritual model for the care of patients at the end of life. The Gerontologist, 42(special issue III):24-33.

The Robert Wood Johnson Foundation (2002). Chronic conditions: Making the case for ongoing care. Prepared by Partnership for Solutions. Baltimore, MD: Johns Hopkins University.

Underwood, L. G. and Teresi, J. A. (2002). The daily spiritual experiences scale: Development, theoretical description, reliability, exploratory factor analysis, and preliminary construct validity using health-related data. The Annals of Behavioral Medicine, 24(1):22-33.

Wheaton, B. (1985). Models for the stress-buffering functions of coping resources. Journal of Health and Social Behavior, 26, 352-364. 